\title{
ANTHROPOGENIC MARINE DEBRIS ACCUMULATION IN MANGROVES ON PENANG ISLAND, MALAYSIA
}

\author{
CHEE SU YIN*1, YEE JEAN CHAI ${ }^{1}$, CAREY DANIELLE $^{2}$, YUSUP YUSRI $^{3}$ AND GALLAGHER \\ JOHN BARRY ${ }^{4}$
}

${ }^{1}$ Centre for Marine and Coastal Studies, Universiti Sains Malaysia, 11800, Minden, Penang, Malaysia. ${ }^{2}$ Natural Resource Wales, Cambria House, 29 Newport Road, Cardiff, Wales, UK. ${ }^{3}$ Environmental Technology, School of Industrial Technology, Universiti Sains Malaysia, 11800, Minden, Penang, Malaysia. ${ }^{4}$ Institute for Marine and Antarctic Studies, University of Tasmania, Churchill Ave, Hobart TAS 7005, Australia.

*Corresponding author: suyinchee@usm.my

Submitted final draft: 9 March $2020 \quad$ Accepted: 11 April 2020

http://doi.org/10.46754/jssm.2020.08.004

\begin{abstract}
Knowledge on anthropogenic marine debris (AMD) distribution and accumulation dynamics in mangroves is limited. To address this shortfall, abundance, sorting, and diversity parameters of AMD were evaluated in Penang's urban and peri-urban mangroves. Debris were counted and classified across transects parallel to the coastline at progressively higher water marks. Plastic percentages make most of the AMD across all sites. More AMD were retained in the urban sites, consistent with larger population density. Diversity of debris was consistent with land use and livelihood of the population in each area. The greatest differences in abundance, diversity, and evenness were recorded between the lower intertidal zones and the remaining inner transects consistent with sorting towards the coastal edge in favour of plastic items. Differences across transects and sites suggested: 1) the main body of the mangrove efficiently retained debris with little sorting; and 2) debris deposited closer to the edge are increasingly sorted and lost to the water body in favour of smaller plastic items. The findings show that mangroves are vulnerable to accumulation and retention of potentially harmful debris, with evidence of a less efficient retention and selective sorting of materials back to the water body closer to their coastal edges.
\end{abstract}

Keywords: Plastic, non-plastic, pollution, sustainability, management.

\section{Introduction}

Anthropogenic marine debris (AMD) is one of the most serious threats to the environment, economy, and human health. Issues concerning AMD are now recognised internationally, alongside other major global challenges facing the marine environment including loss of biodiversity, ocean acidification, and sea level rise (Williamson et al., 2016). Marine debris include all materials discarded into the sea, on the shore, or brought indirectly to the sea by rivers, sewage, storm water, waves, or winds (NOAA, 2018). The most common materials that make up AMD are plastics, glass, metal, paper, cloth, rubber, and wood (NOAA, 2018). Of these, plastics can form up to $95 \%$ of the waste that accumulate on the shorelines, sea surface, and seafloor (Galgani et al., 2015). Bags, fishing nets, as well as food and beverage containers are the most common plastic items and constitute more than $80 \%$ of litter stranded on beaches (Topçu et al., 2013; Thiel et al., 2013).

AMD can originate from land or the ocean. Land-based debris is accumulated from a variety of sources include littering or dumping, storm water discharges, outflow from industries, poor waste management practices, and occasional extreme natural events (i.e. tsunamis and hurricanes) (Rech et al., 2014; Goto \& Shibata, 2015; Aguilera et al., 2016). Ocean-based debris is the result of bad management practices of cargo ships, fishing vessels, and off-shore oil and gas platforms (Hinojosa \& Thiel, 2009; Watters et al., 2010; Hong et al., 2014). The rise in tourism, agriculture, aquaculture, fisheries, and industrial activities worldwide have aggravated this environmental problem (Newman et al., 2015). With rapid population growth and urbanisation, annual waste generation is expected to increase by $70 \%$ from 2016 levels to 3.4 billion tonnes 
in 2050 (World Bank, 2018), thus stressing the need for management measures for AMD.

Previous studies on AMD accumulation in the marine environment have mostly focused on sandy beaches, which are recommended for marine debris monitoring (Moore, 2008; Cheshire et al., 2009; Browne et al., 2015). However, the findings and lessons learnt from beaches cannot be extrapolated to more valuable coastal vegetated ecosystems such as mangroves (Costanza et al., 2014). Beaches are more open and dynamic. Here longshore drift and daily ebb tides on an uninterrupted beach landscape result in a less than efficient rate of retention (Asensio-Montesinos et al., 2020; Williams \& Tudor, 2001). This can lead to variable rates of daily and monthly accumulation and variable stocks (Erikson \& Burton, 2003). Conversely, mangrove ecosystems have complex network of trees and root systems. This complex landscape results in characteristically less dynamic and more efficient retainer and accumulator of AMD even at low densities (Martin et al., 2019; Cordeiro \& Costa, 2010). Their tendency to accumulate AMD is exacerbated by the structure of their pneumatophores (Martin et al., 2019), analogous to a fishing net that retains objects as they pass through and embeds them within its structure or the muddy substrate.

How and what AMD is accumulated within the mangrove canopy will conceivably depend on a range of factors. Firstly, environmental: seasonality (i.e. rainfall) (Araújo \& Costa, 2007; do Sul \& Costa, 2013); hydrology (i.e. waves, currents, tides, local wind) (Nagelkerken et al., 2001; Silva-Iniguez \& Fischer, 2003; Schlining et al., 2013); coastline geography and sediment characteristics (i.e. muddy, sandy and the extent of foreshore preceding the mangroves) (Debrot et al., 1999; Cunningham \& Wilson, 2003; Mordecai et al., 2011). Secondly, system entry sources (i.e. rural, peri-urban, urban, aquaculture, agriculture, industry, residential, commercial) (Santos et al., 2005; Sánchez et al., 2013; Leite et al., 2014) that characterise the debris, that is, the size, weight, and type of the debris (do Sul et al., 2014; Possatto et al., 2015; Martin et al., 2019), can be covariant with population density. Urban to rural environments, by their nature, support a gradient of population densities and a different mix of population activities and livelihoods

The propensity of mangrove forests for accumulation, is its strength in the protection of the coastline but its weakness is in accumulating AMD, causing detrimental, long-term effects to the ecosystem. Indeed, these blue carbon ecosystems are becoming increasingly threatened by AMD accumulation. No less so across subtropical and tropical shores (Hamilton \& Casey, 2016), where mangrove forests cover about $132,000 \mathrm{~km}^{2}$. These forests are an integral part of the coastal environment and their functions and services provide for the well-being of flora and fauna on multiple trophic levels. Their key roles include carbon sequestration (McLeod et al., 2011; Almahasheer et al., 2017), coastal protection, habitat for marine life (Spalding et al., 2010; Duarte et al., 2013), and serve as a stop-over point for migratory birds (Yeok et al., 2016). They maintain water quality and clarity, filter pollutants and nutrients which can lead to algal blooms, and trap sediments originating from land (NOAA, 2018). Mangrove provisions are conservatively estimated to be worth USD 186 million each year in terms of contribution from fisheries, timber and plant products, coastal protection, and tourism (WWF, 2019).

Considering the forests' social, economic, and ecological importance of the forest, the issue of marine debris accumulation in mangroves has been largely neglected (Debrot et al., 2013). The paucity of research of AMD accumulation in mangroves is apparent in that only a handful of studies have been reported with most of them focusing on microplastic in mangrove sediments (Nor \& Obbard, 2014; Lourenço et al., 2017; Naji et al., 2017). In the meta-analyses of spatial and temporal patterns of stranded intertidal marine debris worldwide in which 104 published scientific papers were reviewed, only four studies were found to involve mangroves (Browne et al., 2015). A further review of these four studies 
revealed only one had been conducted under the mangrove canopy itself (Cordeiro \& Costa, 2010) whilst the remaining were carried out in creeks and beaches (Ganesapandian et al., 2011; Singare, 2012; Debrot et al., 2013). The study conducted within the canopy had concentrated on the different densities at high and low tides and did not include a diversity and evenness analyses (Cordeiro \& Costa, 2010).

There is also a paucity of information on where AMD tend to accumulate and whether their accumulation is selective at different parts of the mangroves. To date, only two studies have addressed some of these concerns (do Sul et al., 2014; Martin et al., 2019). The study by do Sul et al. (2014) was limited in the choice of AMD. It focused on the retention and exportation of a selected number of plastic forms deliberately released in mangrove habitats. The study by Martin et al. (2019), on the other hand, considered debris supplied from the open ocean. However, their study across the Red Sea supported a less than congested set of population centres, unlike regions such as Malaysia and the rest of Southeast Asia currently under pressure from AMD pollution. Nevertheless, both studies suggested that retention is a function of the mangrove and debris structures, but no indication of how this affected the overall retention or selection throughout the canopy.

To address the gap, first assessments were carried out in Penang, a city-state located on the northwest coast of Peninsular Malaysia. Penang Island has $6.8 \mathrm{~km}^{2}$ mangroves left, much of which are constantly under threat from land use changes and marine pollution (Chee et al., 2017). The population relies on the many ecosystem services provided by mangroves through fisheries, wood harvesting, and tourism, to supplement the income of this state (Hamdan et al., 2012). The mangroves on the west coast of the island was also attributed for protecting the people and property during the 2004 Andaman tsunami (Alongi, 2008) that claimed over 250,000 lives worldwide-52 in Penang Island alone. With the increase in the pollution reports (Hezri, 2019) and frequency and severity of natural disasters due to climate change (Cheal et al., 2017), the city-state could substantially benefit from the findings of this study. Here we aim to characterize the different forms of debris across urban and peri-urban mangroves in Penang, constrained by changes in wind field and neap tidal cycles. Sorting and retention of these forms were assessed from the changes in diversity, abundance, and evenness through the canopy, from close to the coastal edge and into the main body of the mangrove stands.

\section{Methodology}

\section{Study area}

The study was conducted in two urban and two peri-urban mangroves on Penang Island (Figure 1). These urban and peri-urban mangroves were categorized based on population density and land use as, in a previous study (Nordhaus et al., 2019). Jelutong (JEL) and the Free Trade Zone (FTZ) represented the urban sampling sites. Jelutong is located on the east coast next to a highway, between a landfill and a fishing village, next to a highway. In terms of population livelihood and density at this site, there was some stratification to the north and south, but generally, none between the edge and body of the mangroves. The Free Trade Zone, on the other hand, is located on the southeast coast in an industrial zone. This sampling site is adjacent to Sungai Kluang which is fringed by mangroves and stilted residences on the riverbank. There is no gradient in the population density and livelihood between the edge and the body of the mangroves, here.

Pantai Acheh (PA) and Balik Pulau (BP) represented the peri-urban sites. Balik Pulau on the southwest coast has a slightly higher population and is more urbanised. There is a mangrove forest reserve here, but large swathes of it are under threat to aquaculture and highway construction. Pantai Acheh is a coastal village on the north-west of Penang Island. It is the least urbanised and the most sparsely populated. There is a small fishing facility in the mangroves but, due to the remote location, there is far less human activity and disturbances in comparison to the other sites. Sampling sites and transect 

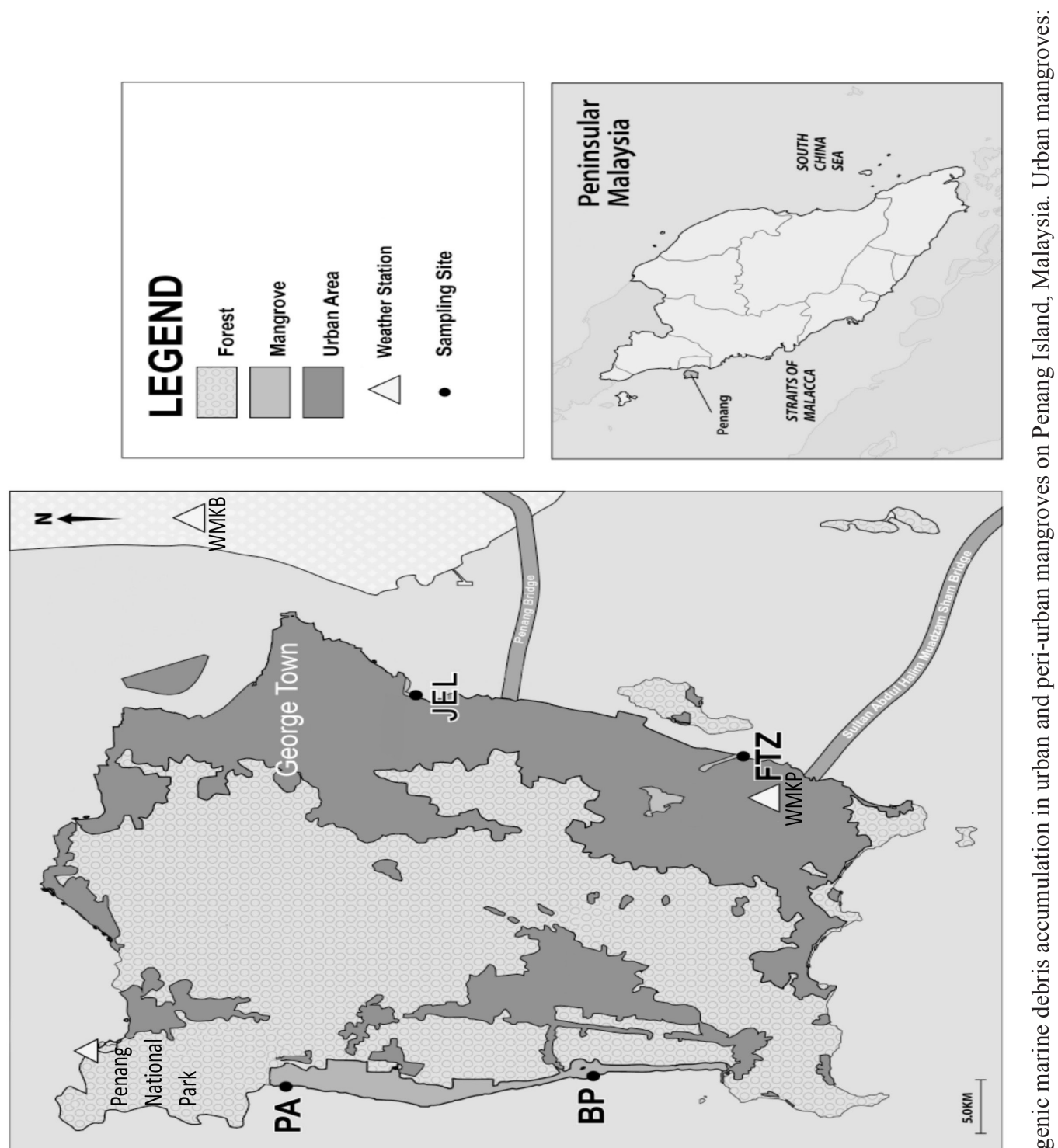

पै लै

츠

क⿺⿻一⿰冫⿰亅⿱丿丶丶⿱⿰㇒一乂

芚

สี

声

항

를

ีㅠำ

$\exists$

ธิ

클

䧈

ठ্ঠ

. $N$

욤

竞

.

可

80
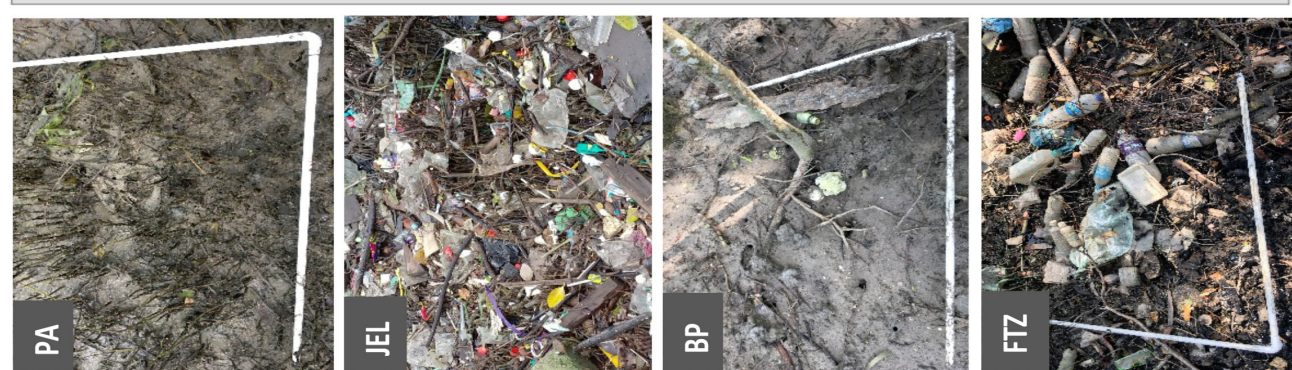

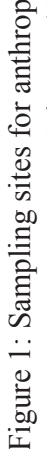




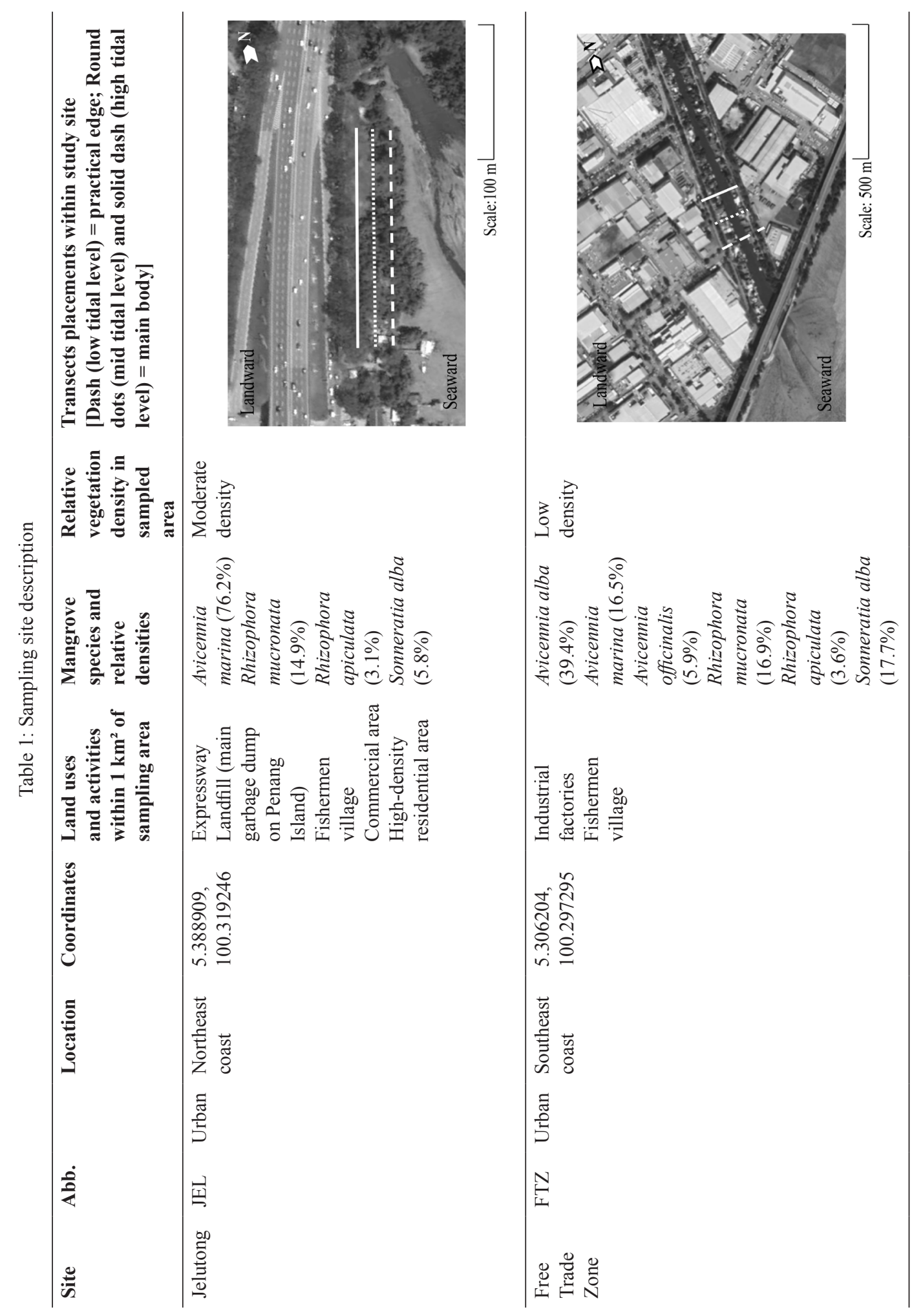


details are presented in Table 1.

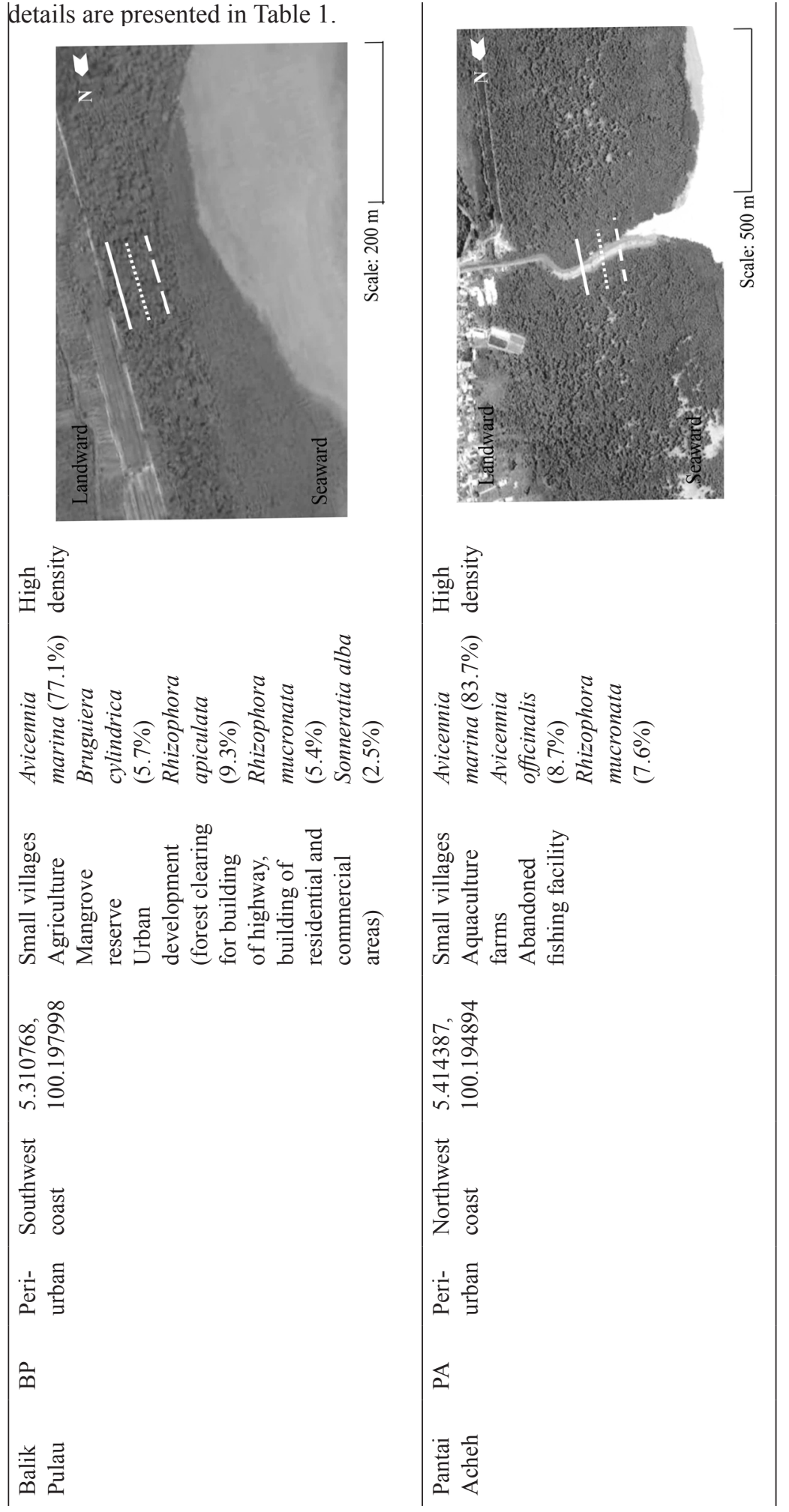




\section{Anthropogenic marine debris (AMD)}

Assessments were carried out between October and November 2018 over the monsoon transition period. The tidal range during this period was $0.5-2.7 \mathrm{~m}$. For all four sites, three transects were placed parallel to the coastal edge (Table 1). The transect at the low tidal level ran as close as possible to the edge of the sea (henceforth referred to as the practical edge) and the other two transects were placed in the main body of the mangroves at mid and high tidal levels. Assessments of the total number and types of AMD for three $10 \times 10 \mathrm{~m}\left(100 \mathrm{~m}^{2}\right)$ quadrats were completed on each transect, totalling in 9 quadrats per sampling site. For more effective data collection, these quadrats were divided into one hundred $1 \mathrm{~m}^{2}$ sub-quadrats.

\section{Classification of AMD}

Diversity indexes were chosen to describe differences in debris composition found in this study. To facilitate data analyses, AMD found in this study were classified as such:

\section{Mangrove}

Vegetation data was collected within $10 \times 10 \mathrm{~m}$ quadrats. Three sampling quadrats were placed in three transect rows parallel to the ocean. The first transect row was set as close as possible to the fringe of the mangrove forest and the following two rows were placed in increasing, equal distance behind the first. In total, twelve $100 \mathrm{~m}^{2}$ quadrats were placed at each of the four study sites. Data collection was modified to fit at urban sites JEL and FTZ due to the thin mangrove areas expanding only 10 meters inwards from the coastline. Within each plot all mangrove species were identified by visual analysis of leaves, flowers, propagules, bark, and fruits using various mangrove guides (Kitamura et al., 1997; Primavera et al., 2004; Giesen et al., 2006). For specimens found to be difficult to identify in the field, samples of propagules and flowers were brought back to the laboratory for identification. The number of mangrove trees in each $100 \mathrm{~m}^{2}$ plot was recorded and the relative density for each species is reported in Table 1.

\begin{tabular}{lcc}
\hline & \multicolumn{2}{c}{ Marine debris } \\
\hline Kingdom & Synthetic origin & Natural origin \\
Phylum & Plastic & Non-plastic \\
Class & Type e.g. foam, sheet, film, fragment & Type e.g. glass, wood, paper, rubber \\
Order & Category of usage e.g. packaging, sanitary, fishing gear, food and beverage, smoking \\
Family & UNEP / IOC litter code (Cheshire et al., 2009) \\
Genus & E.g. plastic bottle, fishing net, tissue paper, cigarette butt, tyre \\
Species & E.g. country of origin, manufacturer \\
\hline
\end{tabular}




\section{Wind and tide}

Projected daily tidal ranges for September to December 2018 were obtained from tide tables (MetMalaysia, 2017). Hourly wind speed and direction data for the same period were obtained from three weather stations: WMKB $\left(5.4659^{\circ} \mathrm{N}\right.$, $\left.100.3912^{\circ} \mathrm{E}\right), \mathrm{WMKP}\left(5.2971^{\circ} \mathrm{N}, 100.2769^{\circ} \mathrm{E}\right)$, and a research station in the Penang National Forest Reserve $\left(5.49^{\circ} \mathrm{N}, 100.2025^{\circ} \mathrm{E}\right)$. The wind rose was plotted using the "openair" package in R (Carslaw \& Ropkins, 2012).

\section{Data analyses}

Mean, standard deviation, and alpha diversity indices were calculated based on untransformed abundance data for each sampling site. Alpha diversity indices were set to the level based on AMD classification codes of type and subtypes, and included: (1) Shannon-Wiener diversity index $(\mathrm{H})$, the measure of diversity based on species richness and their relative frequency; and (2) Species evenness (EH), the measure of heterogeneity of a community based on distribution of relative frequency of species. A high $\mathrm{H}$ index would imply a diverse community structure while a high EH index would indicate an equally distributed community.

To address the similarity in terms of AMD community among the urban and periurban sampling sites, nMDS ordination was used to visualise and interpret grouping of sites in accordance to multivariate community composition based on Chord similarity index. At the same time, analysis of similarity (ANOSIM) was used to statistically test whether there was a significant difference among all four sampling sites. If groups of sampling sites were different in their community composition (AMD type), then the compositional dissimilarities between groups would be higher than that within groups. Hence, ANOSIM R is based on the difference of mean ranks between groups and within groups. When a significant difference was detected, pair-wise post-hoc test was used to examine the correlation between groups. A large positive $\mathrm{R}$ value $(-1$ to +1$)$ would signify dissimilarity between groups whereas 0 would indicate random grouping.

To address potential tidal fluctuation effect on AMD retention, we performed two-way ANOSIM test for each tidal level (low, mid and high) crossed between each sampling site. In addition, Similarity Percentage (SIMPER) with Chord similarity measure was performed to assess which taxa were primarily responsible for the difference between each tidal level within groups. All statistics were performed using Paleontological Statistics software package (PAST) version 3.22. A tidal curve was also generated using average daily means and subsequently smoothed with a 2 -week moving average to illustrate variance over the springneap cycle in PAST. Raw data was submitted to Mendeley Data (Chee et al., 2019).

\section{Results}

\section{Site Specific Anthropogenic Marine Debris}

\section{Abundance}

Mangrove stands with the greatest AMD abundance were found along transects within the densely populated urban areas on the east coast of Penang Island. In JEL, which is located to the north and next to the island's main landfill, the highest abundance was recorded at a total of 7,312 items (Table 2). Of these, $92.5 \%$ were plastic materials while the remaining $7.5 \%$ were non-plastics (Figure 2). Plastic debris ostensibly comprised plastic bags as the largest fraction, followed by plastic sheets, and cutlery (Figure 3a). Non-plastic materials consisted mainly of glass and ceramic, followed by cloth, and rubber (Figure 4). The other urban site in the south, FTZ, which is located within the island's industrial zone, 1,258 items were recorded. Of these, $77.7 \%$ were plastics (Figure 2). Like JEL, plastic bags contributed the highest number of plastic followed by plastic sheets and cutlery (Figure 3b) with non- plastic items following a similar hierarchy (Figure 4) of glass and ceramic, rubber, and cloth. Other plastics items found within the urban mangroves include bottles, bottle lids, food containers, fishing nets, lighters, 
cigarette butts, mesh bags, foam, and fragments. Non-plastic items like paper, cardboard, and metal were also spotted.

The sparsely populated peri-urban sites on the west coast had notably lower abundances of AMD. The peri-urban site to the south of the island, BP, which is located within a mangrove reserve, recorded 1,001 items. Plastic items constituted most of the AMD items (87.2\%) in Figure 2. Unlike the other sites, plastic fragments dominated followed by bottles and sheets (Figure $3 c)$. This site was in part distinctive in that it diverted from the usual island site hierarchy for non-plastics, with metals emerging as dominant, followed by cloth, and rubber (Figure 4). Other plastic items found in the peri-urban mangroves were plastic bags, food containers, cutlery, bottle lids, six pack rings, fishing nets, and foam.

Located at an abandoned fishing facility to the north of the island, PA recorded the least abundance of AMD of all the four peri-urban and urban sites, with 215 items. Of these, $75.3 \%$ were plastics (Figure 2). In contrast to the urban sites, within PA, fishing nets were the most common plastic items found followed by sheets and plastic bags (Figure 3d) but with a similar non-plastic hierarchy (Figure 4) of glass and ceramic, rubber, and cloth. Non-plastic items such as paper and cardboard were found in BP but not in PA.

\section{Diversity}

The diversity of AMD was found to be similar for all sites (Table 2). The highest diversity $\left(H^{\prime}=2.65\right)$ was recorded in FTZ whilst the lowest diversity $\left(\mathrm{H}^{\prime}=2.15\right)$ was recorded in BP. Evenness was similar among JEL $(\mathrm{H}=0.26), \mathrm{FTZ}$ $(\mathrm{H}=0.31)$ and $\mathrm{BP}(\mathrm{H}=0.30)$ but significantly lower in PA $(H=0.58)$. Nevertheless, despite the similarity a significant difference was detected in the AMD "community" among sampling sites ( $\mathrm{p}=0.0003, \mathrm{R}=0.5864$, Table 3 ).

Correspondingly, the nMDS plot revealed three clusters: 1) PA (peri-urban), 2) BP (periurban), and 3) JEL and FTZ (both urban) (Figure 5). SIMPER analysis showed that dissimilarity between the urban sites, FTZ and JEL, was low $(11 \%)$ and confined to differences in relatively high numbers of bottle caps and ceramic construction material (a cumulative 44\%) across the mangrove stands. Comparisons between the rest of the sites showed differences in AMD "community" with the largest dissimilarity (91\%) between BP and PA contributed by fishing nets in PA and fibreglass fragments in BP. In total, these two types of debris cumulatively accounted for $76 \%$ dissimilarity between the two sites. The percentage of dissimilarity was similar between JEL and BP (77\%) and JEL and PA (78\%). Between JEL and BP, the differences were mainly contributed by fibreglass fragments and plastic bags in JEL (71\%), whilst between JEL and PA the differences were largely contributed by plastic bags and cutlery in JEL (78\%). Percentages of differences were lower between FTZ and BP (58\%) and FTZ and PA $(58 \%)$. Fibreglass fragments in BP and plastic bags in FTZ contributed most of the dissimilarity (65\%) between FTZ and BP, whilst fishing nets in PA contributed $55 \%$ of the dissimilarity between FTZ and PA.

\section{Anthropogenic Marine Debris Variability Within Sites}

On a rising neap-spring tide (Figure 6), patterns of AMD accumulation at different tidal levels were similar in the two urban mangroves. Abundances of AMD in JEL and FTZ were lower at the practical edges than in the main body of the mangroves (Figure 7). Although not significantly different, the differences in the abundance of AMD accumulated at the practical edge versus the main body was more pronounced in JEL than in FTZ. In JEL, closest to the edge, showed the greatest transition in AMD abundance from the practical edge to the main body. The practical edge recorded lower diversity $\left(\mathrm{H}^{\prime}=0.64\right)$, whilst the main body recorded similar and higher diversities $\left(H^{\prime}=2.14\right.$ to 2.24$)$. Evenness was higher at the practical edge $(\mathrm{H}=0.95)$ compared to the main body $(\mathrm{H}=0.26$ to 0.31$)$. 


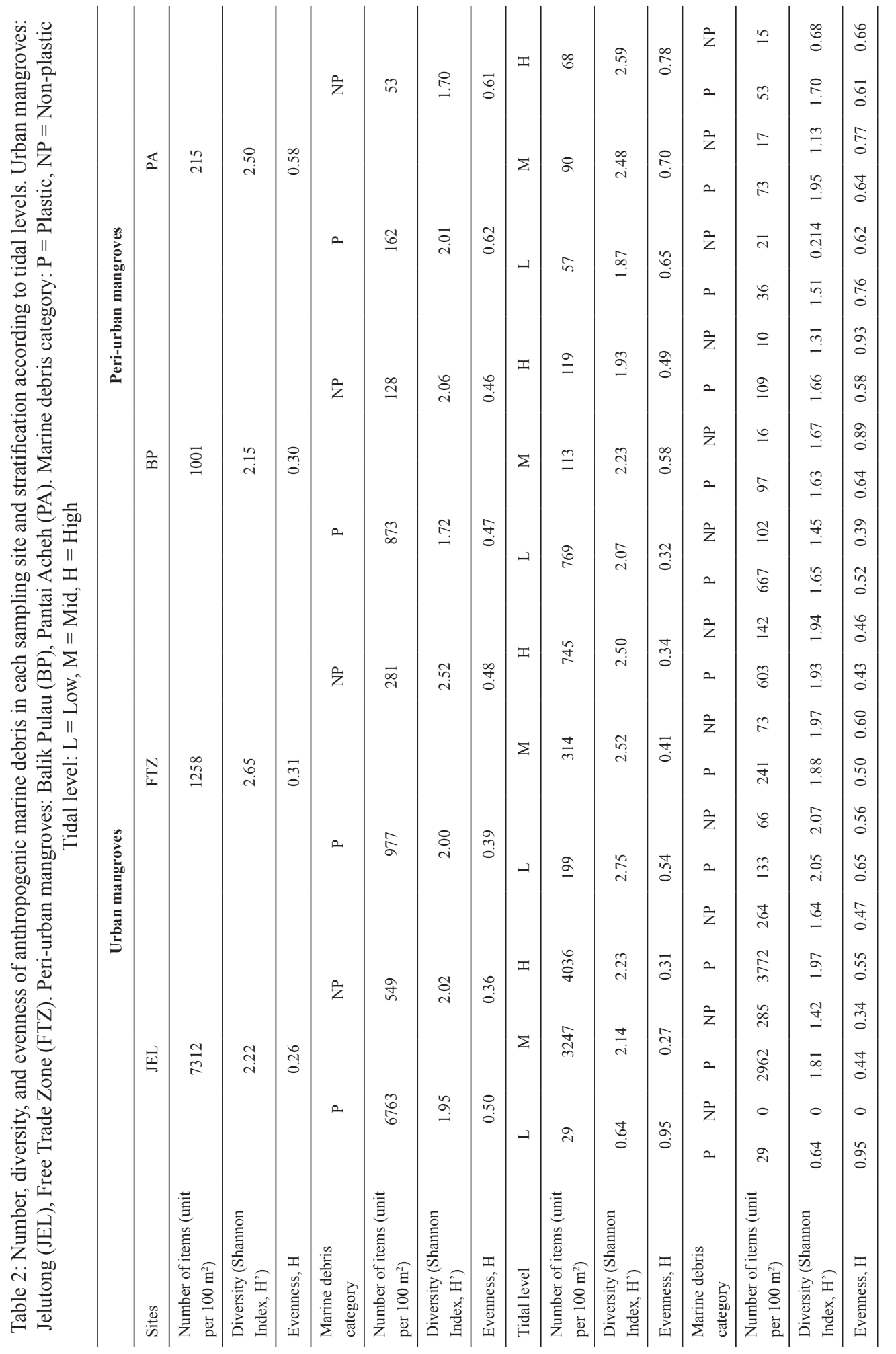




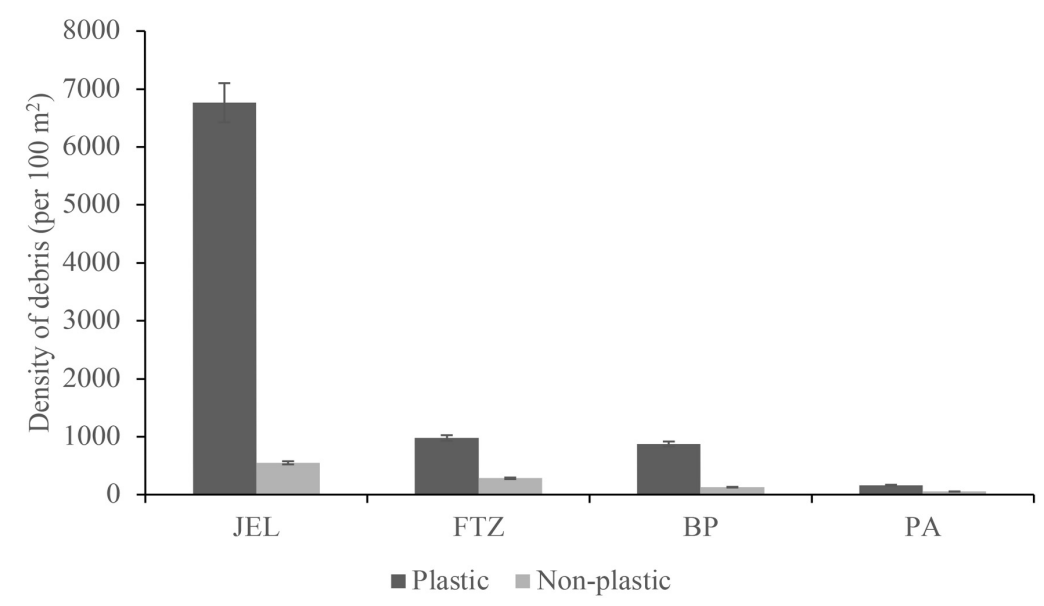

Figure 2: Density of plastic versus non-plastic items $100 \mathrm{~m}^{-2}$ accumulated at Jelutong (JEL), Free Trade Zone (FTZ), Balik Pulau (BP) and Pantai Acheh (PA). The error bars represent standard deviation from the total number of quadrats $(n=30)$. In all cases, the densities of plastic items were greater than non-plastic items within each site

In FTZ, which was slightly further from the edge, the transition was less pronounced. Similar diversities were observed throughout the tidal levels ranging from $\mathrm{H}^{\prime}=2.50$ to 2.52 in the main body to $\mathrm{H}^{\prime}=2.75$ at the practical edge. Evenness here was higher at the practical edge $(\mathrm{H}=0.54)$ compared to the main body $(\mathrm{H}=$ 0.34 to 0.41 ). While abundances were different within the main bodies of urban sites, diversity and evenness were similar. However, in the case of the practical edges, differences in diversity were detected. SIMPER analyses revealed that this was mainly attributed by the accumulation of plastic cutlery, sheets, bottles, and bags in the main body of JEL, and the retention of plastic cutlery at the practical edge as well as plastic bottles, sheets, construction material, and fibreglass fragments in the main body of FTZ (Table S1).

The peri-urban sites, which were both sampled on a falling neap-spring tide, displayed either decreasing or variant patterns in terms of AMD accumulation. The practical edges in these two sites were further inland compared to the practical edges in the urban sites. In contrast to the urban sites, BP displayed a decreasing pattern. Debris abundance was higher at the practical edge and lower through the main body. Although abundances were different, the diversity and evenness remained similar. Diversity ranged from $\mathrm{H}^{\prime}=2.07$ at the practical edge to $\mathrm{H}^{\prime}=1.93$ to 2.23 in the body of the mangroves while evenness ranged from $\mathrm{H}=0.32$ at the practical edge to $\mathrm{H}=0.49$ to 0.58 in the body of the mangroves. Differences in diversity between the practical edge and the main body were mainly caused by the accumulation of fibreglass and plastic bottles at the practical edge (Table S1).

PA, inconsistent with the rest of the sites, displayed a variant pattern with higher AMD abundance in the mid intertidal zone compared to the practical edge and high intertidal zone. The practical edge had a slightly lower diversity $\left(H^{\prime}=1.87\right)$ compared to the main body of the mangroves $\left(\mathrm{H}^{\prime}=2.48\right.$ to 2.59$)$. Evenness was slightly elevated in the high intertidal zone $(\mathrm{H}=$ $0.78)$ compared to the practical edge $(\mathrm{H}=0.65)$ and the mid intertidal zones $(\mathrm{H}=0.70)$. The differences in diversity between the practical edge and the main body in PA were almost wholly induced by the retention of construction material seemingly directly dumped at the practical edge, as well as fishing nets and bottles in the main body of the mangroves (Table S1). 


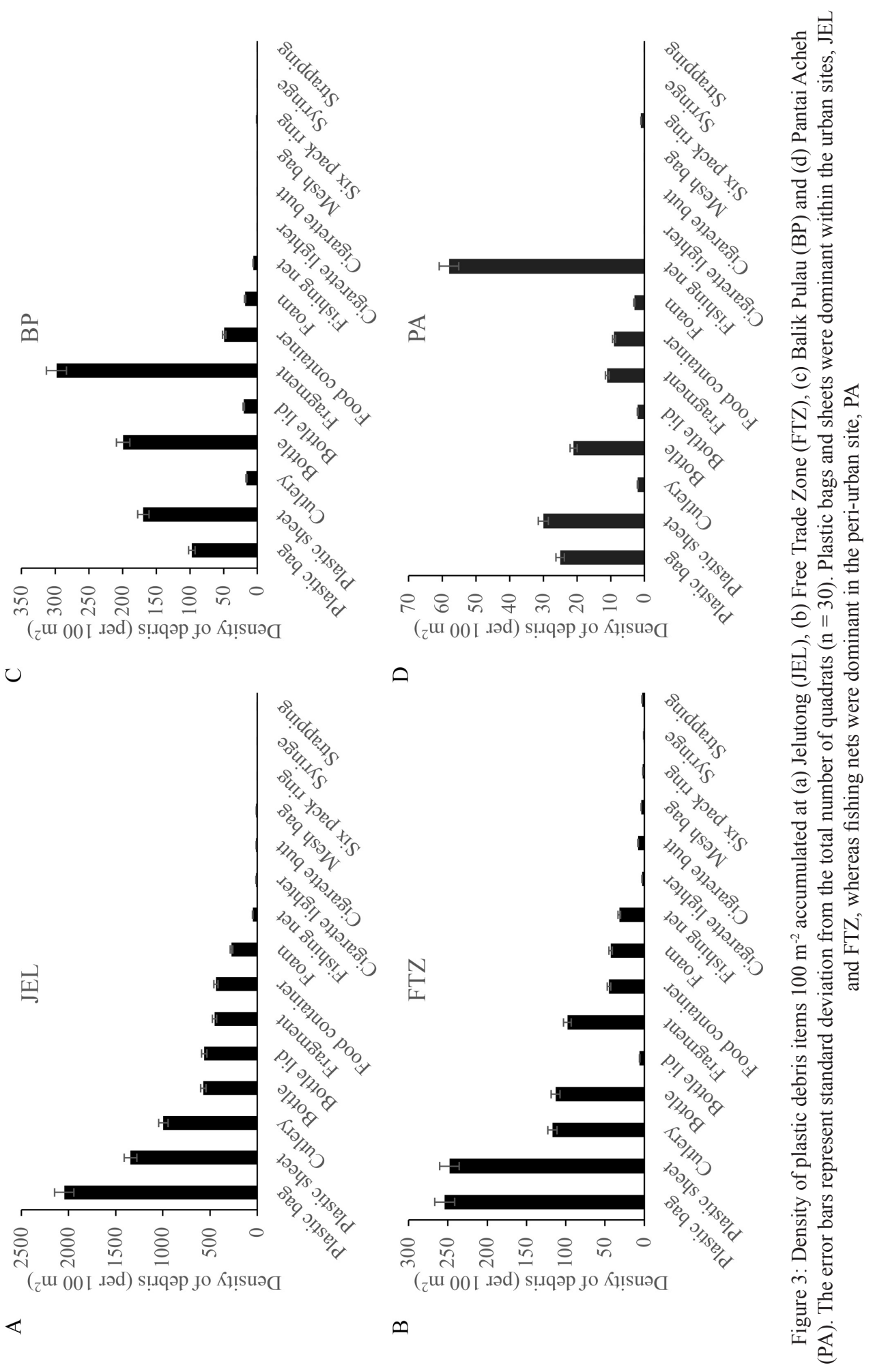




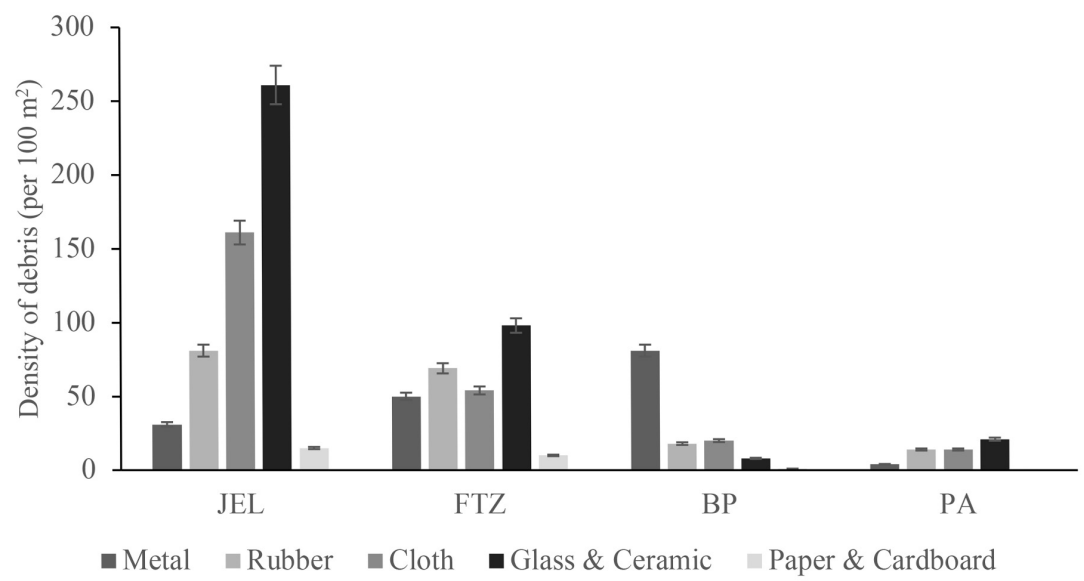

Figure 4: Density of non-plastic debris items $100 \mathrm{~m}^{-2}$ accumulated at Jelutong (JEL), Free Trade Zone (FTZ), Balik Pulau (BP) and Pantai Acheh (PA). The error bars represent standard deviation from the total number of quadrats $(\mathrm{n}=30)$

Table 3: ANOSIM pairwise table (post-hoc R-values). Values indicate degree of similarity between accumulated marine debris in peri-urban $(\mathrm{BP}=$ Balik Pulau, $\mathrm{PA}=$ Pantai Acheh $)$ and urban sites $(\mathrm{FTZ}=$ Free Trade Zone, JEL $=$ Jelutong $) . *$ indicate significant values $(\mathrm{p}<0.05)$

\begin{tabular}{ccccc}
\hline & FTZ & JEL & BP & PA \\
\hline FTZ & & & & \\
JEL & -0.04 & & & \\
BP & 0.78 & 1 & & \\
PA & 0.52 & 0.70 & 0.74 & \\
\hline
\end{tabular}

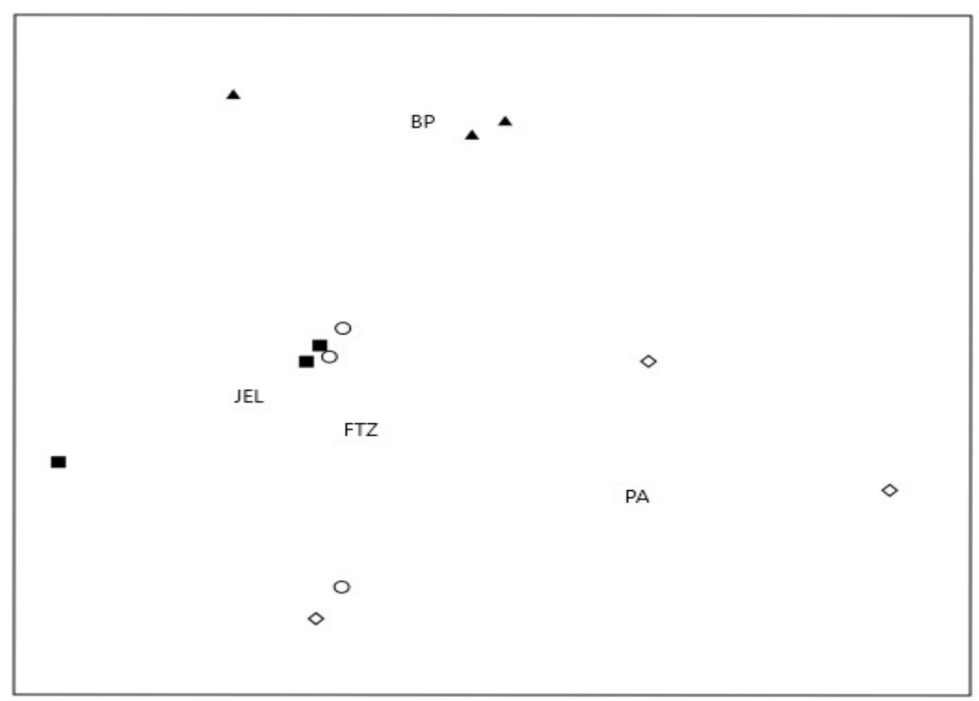

Figure 5: nMDS plot of relationship between urban $(\square \mathrm{JEL}=$ Jelutong and $\circ$ FTZ $=$ Free Trade Zone $)$ and peri-urban $(\diamond \mathrm{PA}=$ Pantai Acheh and $\boldsymbol{\Delta} \mathrm{BP}=$ Balik Pulau $)$ sites . 


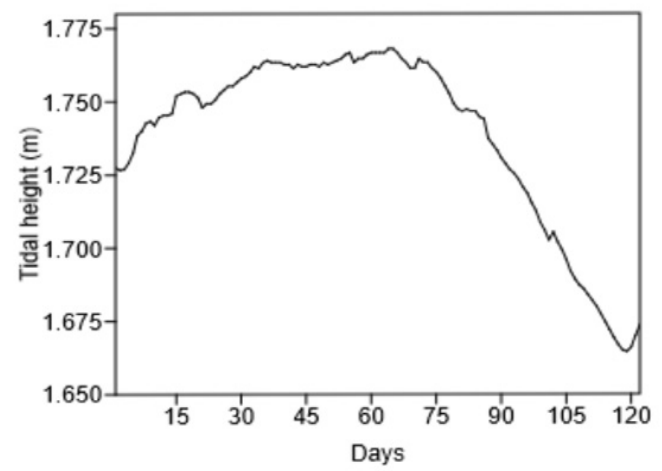

Figure 6: Monthly tidal range from September to December 2018 smoothed by moving average at 14 points $(\alpha=0.50)$

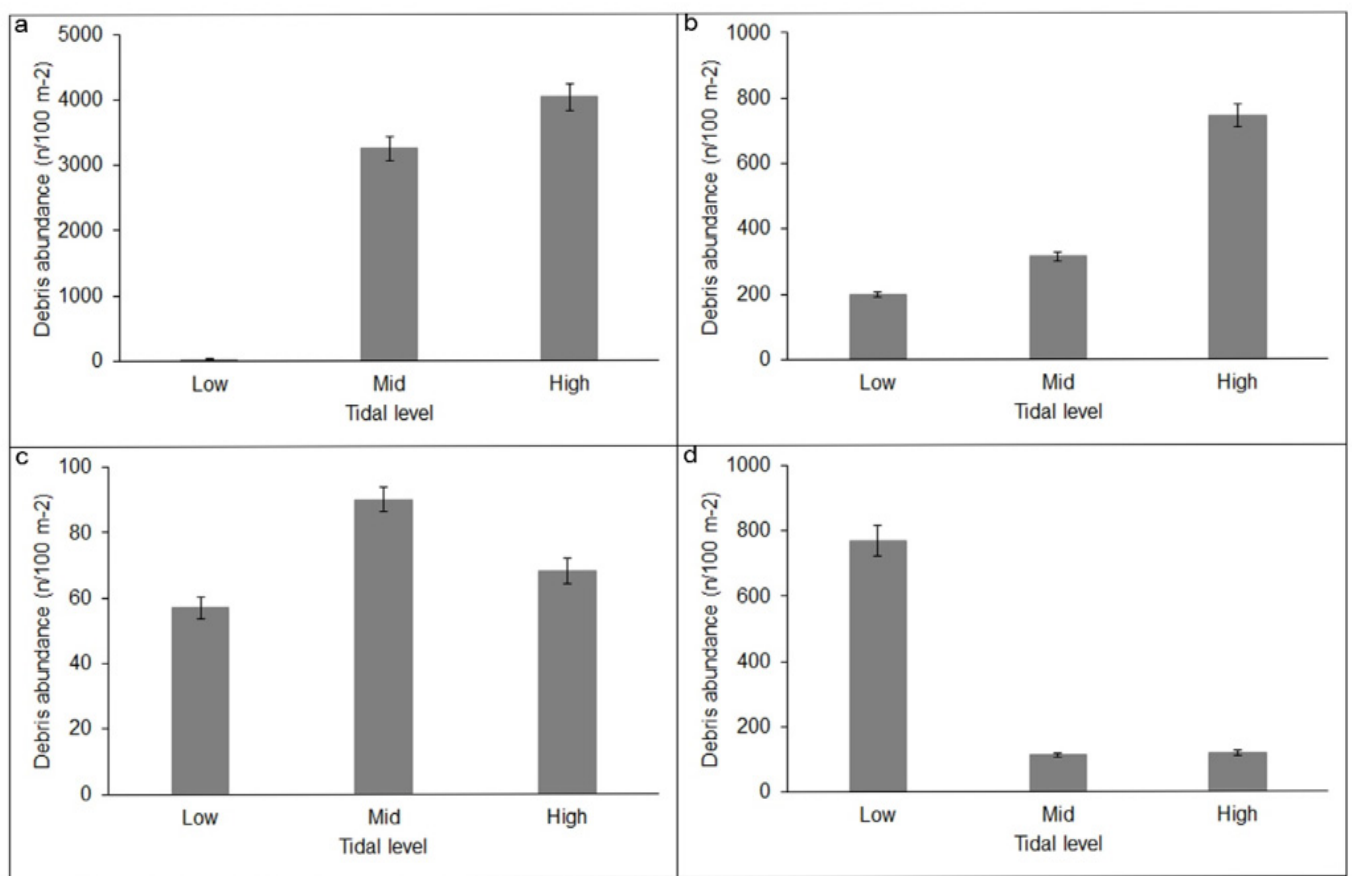

Figure 7: Abundance of anthropogenic marine debris accumulated at different tidal levels at (a) Jelutong (JEL), (b) Free Trade Zone (FTZ), (c) Pantai Acheh (PA), and (d) Balik Pulau (BP)

To eliminate possible influence of direct dumping of dominant AMD at the two periurban sites, additional analyses were performed with these items removed. After removing construction material from $\mathrm{BP}$ and $\mathrm{PA}$, as well as fishing nets from PA, we found that there were no differences in abundance, diversity and evenness.

\section{Mangrove Diversity and Relative Density}

Avicennia marina was the dominant species at all sites (ranging from $76.2 \%$ in JEL to $83.7 \%$ in PA) except in FTZ where $A$. alba was dominant $(39.4 \%)$ as seen in Table 1. Rhizophora mucronata was present in all sites. Sonneratia alba and Rhizophora apiculata were present in all sites except PA and in lower densities (S. alba $=2.5 \%$ in $\mathrm{BP}$ to $17.7 \%$ in FTZ; $R$. apiculata $=$ 
$3.1 \%$ in JEL to $9.3 \%$ in BP) compared to the former two species. Bruguiera cylindrica was only present in $\mathrm{BP}$ at $5.7 \%$ relative density and Avicennia officinalis was only present in FTZ at $5.9 \%$ relative density.

\section{Wind and Tide}

Throughout the sampling period, wind fields at the three weather stations did not vary before, during, and after the sampling period (SeptemberDecember 2018). Wind fields were dominant at the northwest quadrant in Butterworth, southwest quadrant in Bayan Lepas, and south quadrants in Penang National Park (Figure 8). Urban sites were sampled during a rising neapspring tide whilst peri-urban sites were sampled during a falling neap-spring tide. a

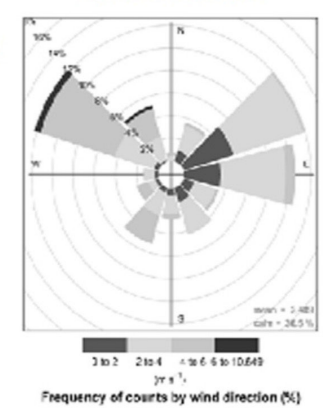

September 2018

b

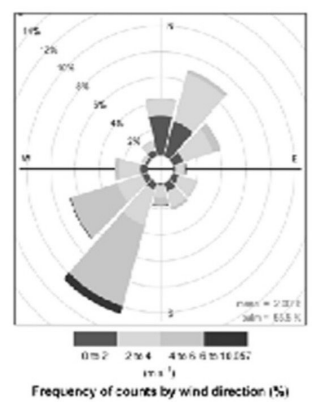

September 2018

c

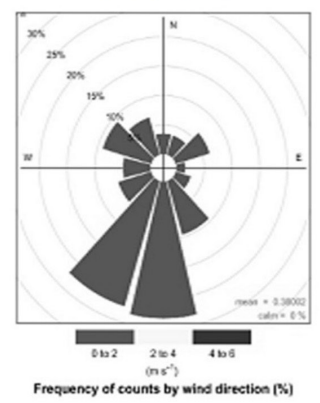

October 2018

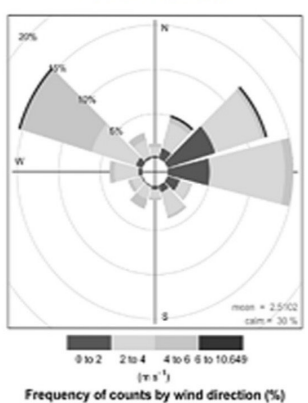

October 2018

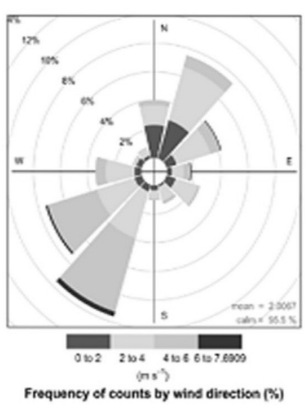

October 2018

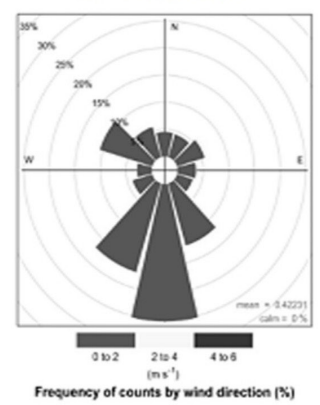

Nove mber 2018

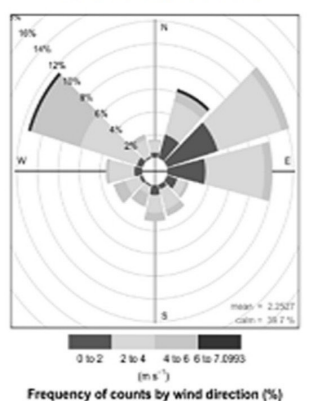

November 2018

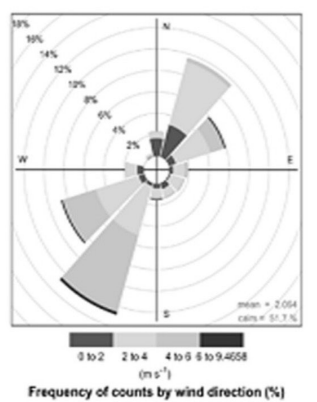

November 2018

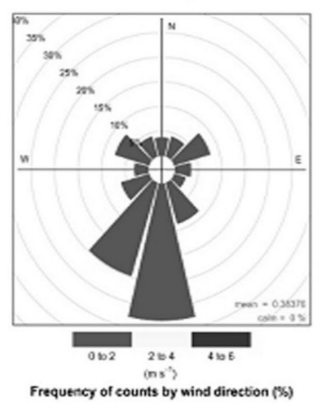

December 2018

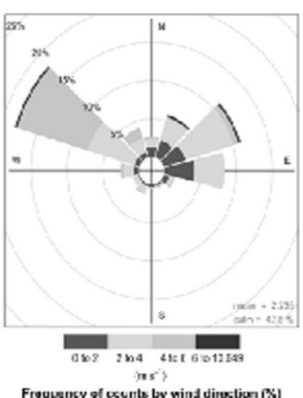

December 2018

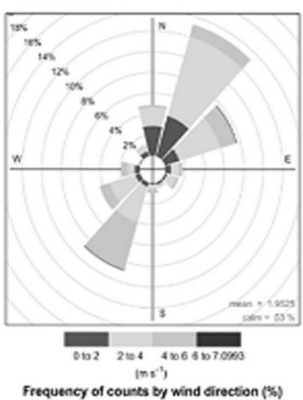

Dece mber 2018

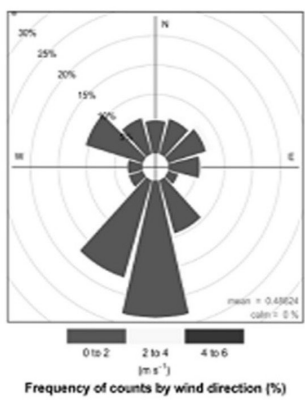

Figure 8: Wind rose plots retrieved form weather stations in (a) Butterworth / WMKB, (b) Bayan

Lepas / WMKP, and (c) Penang National Park 


\section{Discussion}

\section{Anthropogenic Marine Debris Composition}

The dominance of plastic items observed at all sites supports the plethora of global studies that have quantitatively described marine debris from beaches (Ryan et al., 2009; Leite et al., 2014; Possatto et al., 2015; Asensio-Montesinos et al., 2020) and mangroves (Sivasothi, 2002; ICCS, 2009). This recurring pattern of plastic contamination reflects its versatility and subsequent wide-scale high use by modern society, variability, low-density (i.e. propensity to float), and resilience to environmental degradation (Derraik, 2002; Katsanevakis \& Katsarou, 2004).

The abundances of different AMD classes are consistent with the dominant human activity at each site (Abu-Hilal \& Al-Najjar, 2004). Large proportions of plastic bags, food containers, bottles, and cutlery were found in urban sites, while fishing nets, plastic sheets, bags, and bottles were found in greater magnitudes in peri-urban sites, because of their environmental persistence, ample utilization, and low reuse and recycling rates, as has been observed in other regions (Derraik, 2002; Santos et al., 2005; Cordeiro \& Costa, 2010). In particular, JEL, located adjacent to the Jelutong Landfill (the main garbage dump on Penang Island), had almost six times more AMD compared to FTZ. The landfill had recently been reported to be operating over its capacity and potentially causing harm to the environment (Mok, 2019). In FTZ, located in an industrial zone with round-the-clock human mobility, occurrences of fibreglass, construction material, and cutlery were the highest. In the peri-urban sites, $\mathrm{PA}$ and $\mathrm{BP}$, where fishing was the dominant human activity, more fishing nets and fibreglass fragments (the main material used to build fishing boats), were found.

A positive relationship between the population density and abundance of AMD was observed. The urban mangroves (JEL and FTZ), located on the east coast of Penang Island where most of the island's development (Chee et al., 2017) and population is concentrated, recorded significantly more AMD compared to the peri- urban mangroves (BP and PA) sampled in this study. The relationship between population size and coastal contamination has previously been recorded in several studies (McGranahan et al., 2007; Browne et al., 2011, Browne et al., 2015). Pollution in intertidal areas has been directly linked to the number of inhabitants in its vicinity, leading to largely populated areas having greater amounts of AMD as opposed to less populated areas (Browne et al., 2011; Seto et al., 2011; Yonkos et al., 2014). In this study, population size was potentially the driving factor for higher abundance of AMD in the urban sites, JEL and FTZ, and the elevated number of AMD in BP compared to PA. For the latter, even though both areas are forged from an interaction of urban and rural land use, BP located on the southwest of Penang Island has a considerably higher population density compared to PA on the northwest which consists of a small fishing village.

Aside from population density, other factors such as tree density and the inferred differential ability to retain AMD may be part of the equation. This presumption can be inferred from the abundances of AMD accumulated in the two urban sites. JEL, which had moderate tree density, accumulated higher abundances of AMD compared to FTZ, which had lower tree density (Table 1). It is presumed that mangrove roots can also trap objects (like floating plastic) transported by currents but to date, there is no indication how this affects the overall retention or selection throughout the canopy (Martin et al., 2019). In this study, tree stands and roots were observed to be thinning towards the coastal edge at the urban site, JEL, where the practical edge was at the coastal edge. Coincidentally, AMD was also found to be least abundant at the coastal edge and the number of plastic bags, bottles, cutlery, and food packaging were markedly reduced compared to the main body. Further investigations need to be carried out to test this phenomenon.

\section{Anthropogenic Marine Debris Dynamics}

Eriksson et al. (2013) and Smith and Markic (2013), found that the loss and variance of open 
beach debris appeared to be driven at the scale of semi-diurnal to diurnal falling tides. Sadri and Thompson (2014), also found that this was also the case for the more mobile micro- and macroplastics which also show considerable variation on beaches at small timescales within a day. Therefore, it was initially surprising that we found no evidence for confounding of this retention dynamic at different monthly rising and falling spring-neap cycles. The patterns of abundance, diversity, evenness, and AMD accumulation at each site were either similar or did not require this explanation to describe the variance. The spring-neap relative invariance may well reflect the mangrove systems' less dynamic character over beaches in its greater ability to retain material. In other words, the current mangrove stock is a result of a slow accumulation of material and not a complex beach dynamic balance that depends on the state of the tide and previous accumulated state. Other than tide, it has also been recognised that the rate of supply for net accumulation and sources of AMD are also dependent on the wind field. However, for this study, any differences between sites as the result of sampling at different times was not confounded as it was also observed that these wind fields had remained in the same quarters for each site before and throughout the sampling period.

An edge effect was observed in the urban sites. Abundances were lower but diversities and evenness were higher at the practical edges compared to the main bodies of these mangroves. This is consistent with both sorting and less retention by diurnal tidal movements for which effects are more prominent closer to the coastal edge where tree densities are markedly lower than in the main body. Lower tree densities are presumed to have resulted in less impediments to the free circulation of floating residues (Cordeiro \& Costa, 2010). The edge effect was more prominent in FTZ than JEL in which sorting appeared to retain plastic cutlery over other forms of debris at its practical edge. The effect, however, did not appear to extend through the main body of the mangrove stands. There were higher AMD abundances that showed similar diversities and evenness consistent with relatively unimpeded transport into the mangroves on a rising tide as initially suggested by Cordeiro and Costa (2010), and efficiently retained after deposition. Thus, it appears that not only sorting may be happening towards the edge but there is a general fall in abundance and retention.

The reasons behind sorting and falling retention are unclear. Changes in retention may stem from a change in hydrodynamic parameters, as arguably determined by the mix and density of mangrove structures such as pneumatophores and trunk as well as mud. Generally, pneumatophores are more abundant and longer in deeper water, often represented by the low tidal mark, and more recently seen to be associated with different forms of debris, such as plastic bags and nets (Martin et al., 2019). It is thus, not inconceivable that sorting as a selective retention of the smaller plastic components, as exemplified at JEL, may be the result of changing mangrove structure. Alternatively, the narrow width of the mangroves observed at both urban sites might also allow AMD to be pushed further and higher with each rising tide, with lighter and more buoyant debris (plastic bottles, sheets, and cutlery) having a greater tendency to accumulate there. Indeed, higher grounds have been reported to retain significantly more plastic items (do Sul et al., 2014) with debris most highly concentrated at natural wrack lines (Viehman et al., 2011). Clearly, these speculations require more detailed and extensive measurements of pneumatophores and trunk densities and sizes, not forgetting the role of muddy bottoms for the smaller components.

The edge effect was not as apparent in the peri-urban sites. We suggest that this is a function of practical sampling accessibility, where the practical coastal edges were further inland compared to those in our urban sites. Here, variability was observed throughout the main bodies of the two peri-urban mangroves. Nevertheless, higher abundance was observed at the practical edge in BP. Evenness and diversity were the same at all tidal levels indicating no selection or sorting. The main difference between 
$\mathrm{BP}$ and the peri-urban sites, PA, was the fact that even though the practical edge in BP was not close to the coastal edge, they were at the edge of naturally recruiting mangroves. Prominent differences in densities and arrangements of mangroves stands in the mangrove reserve versus the naturally occurring mangroves on the seaward side were observed during sampling. In fact, difficulty in accessibility into the naturally occurring mangroves was the reason for the placement of the seaward transect at this practical edge. Therefore, although there may not be an edge effect between the planted mangroves in the reserve and the sea, there may be an edge effect between planted and naturally occurring mangrove trees at this site. The naturally occurring mangroves were noticeably denser and are likely the reason for more AMD accumulating at the practical edge, but the nature of this retention is not selective for specific kinds of debris. Through the main body, there was no difference in abundance indicating free movement and translocation of AMD through it. Contradictory to the urban sites, BP was sampled on a falling tide possibly exporting AMD seaward accumulating at the edge of the naturally occurring mangroves. Retention on a rising diurnal tide is also possible and subject to further studies.

Interestingly, while evidence of dumping was most apparent at this peri-urban site, removing this variable did not significantly affect diversity, evenness, and abundance. The greater driver here seems to be the continuous pressed vector of AMD transport into the mangroves from the sea and the ability of the mangroves to retain the AMD, over time. Clearly while dumping should be discouraged, resources directed to this relatively stochastic input would be effectively utilised towards managing debris at their sources and preventing them from entering the oceans.

Monthly tidal regimes seem to have little influence of the abundance, diversity, evenness, and patterns of AMD accumulation at each site. On the contrary, diurnal tidal movements were observed to have a stronger influence on these parameters, aiding sorting in the narrower, urban mangroves, retention in denser mangroves, and intertidal movement in sparser mangroves. This is consistent with previous studies that concluded debris loads could vary considerably between days and accumulation rates estimated from monthly rather than daily collections are underestimated by up to an order of magnitude (Eriksson et al., 2013; Smith \& Markic, 2013). Micro- and macroplastics can be highly mobile and show considerable variation at small timescales, even within one day (Sadri \& Thompson, 2014). It was also observed that differences in said parameters were not constrained by previous wind fields as these wind fields had remained in the same quarters before and throughout the sampling period.

\section{Management Recommendations}

Although more stringent laws and enforcement can help curb the issue of direct dumping in mangroves, controlling this act alone will not significantly decrease the accumulation of AMD in mangroves. Management of debris at the source (e.g. plastic bags in urban mangroves, fishing equipment in peri-urban mangroves) through practices like reducing their generation, reusing, and recycling are recommended and would likely play a bigger role in preventing more debris from entering these ecosystems. Clean-ups can be organized to remove existing AMD, but these should not only concentrate on beaches but also in mangroves which have long been neglected and have greater abilities in retaining debris. Clean-ups in larger magnitudes and capacity are needed in urban mangroves where there are more contributors of debris compared to peri-urban mangroves.

Removal of pollutants should be prioritised in mangrove bodies and denser mangroves where AMD accumulation is higher. The edges of the mangroves should be cleared more frequently compared to the main body to avoid debris from being lost to the water body after which, management would be increasingly difficult. Clean-up programs can be carried out throughout the year as monthly tidal regimes 
were observed to have little to no effect on the abundance, diversity, or evenness of AMD accumulated in mangroves. Most importantly, cleaning operations must be well-planned and carried out by people who have been trained to remove debris from these fragile and sensitive ecosystems. The key mechanism for minimizing AMD in peri-urban areas remains the integration between the local government and civil society, with the former being responsible for regular bulk collection and disposal, and the latter for disposal at clearly identified locations.

Swift action is needed to avoid further accumulation in debris of the mangrove ecosystems. A recurring concern of such debris is the obvious visual pollution and economic repercussions for the tourist and marine industries associated with unwanted material either deposited in the mangroves or entangling and damaging equipment (e.g. Barnes et al., 2009; Derraik, 2002). At an ecosystem level, common items found in this study (i.e. plastic bags, sheets, fragments, fishing nets, glass, ceramics) can negatively influence biota via the absorption of harmful chemicals, transport of non-native marine species to new habitats on floating objects, crushing of vegetation or reduction of light levels needed for growth, causing injuries and death among marine animals, and bioaccumulating up trophic levels (Uhrin \& Schellinger, 2011; Rochman et al., 2013; Vegter et al., 2014). There is also potential link between mangrove pollution and carbon sequestration, as stress from pollution can lead to mangrove mortality and less productive mangrove ecosystems (UN Environment, 2017).

Public awareness, education, as well as advocacy campaigns can help change mindsets by stressing on the importance of conserving mangroves and its effect, otherwise. Constant engagement between researchers and the members of the public in local outreaches can raise awareness and invoke responsible action among individuals. Indeed, the perception of mangroves being idle ecosystems is rapidly being replaced by their recognition as super ecosystems of the tropics and governments are starting to acknowledge mangroves as a key solution even along urban coastline. Besides that, standard operating procedures and management strategies should also be reviewed and revamped periodically to account for changes in the nature of challenges and threats faced by mangroves and continued assessments like this study will inform this.

\section{Conclusion}

In this first assessment of AMD accumulation in selected mangroves in Penang Island, it was found that more AMD was accumulated in urban compared to peri-urban sites, consistent with larger population densities in urban areas. Congruent with previous studies on AMD accumulation in the marine environment, plastics made up most of the AMD in all the sampling sites. Highly diverse debris forms were consistent with land use and population livelihood in each area. At the practical edges within the lower tidal zones of the urban sites, we observed evidence of sorting in favour of plastic items. The greatest differences in abundance, diversity, and evenness were recorded between the lower tidal zones and the remaining inner transects consistent with sorting towards the coastal edge in favour of plastic items. These patterns of change and differences across transects and sites suggested: 1) the canopy and root structure within the main body of the mangrove efficiently retained debris with little sorting; and 2) debris deposited closer to the edge were increasingly sorted and lost to the water body in favour of smaller plastic items, for a constant wind field and irrespective of neap-spring phases. Future studies could include relationships between root types and the mangroves ability to retain debris. Assessments like this should be conducted at regular intervals for a long-term monitoring of AMD accumulation in mangroves as well as management and rehabilitation efforts.

\section{Acknowledgements}

The authors would like to thank the supporting staff at the Centre for Marine and Coastal Studies, Universiti Sains Malaysia, for help on field work and Dr. Foong Swee Yeok (School of 
Biological Sciences, Universiti Sains Malaysia) and Dr. Aldrie Amir (Universiti Kebangsaan Malaysia) for their suggestions and advice during sampling and writing.

\section{Data reference}

Chee, Su Yin; Gallagher, John Barry; Yusup, Yusri; Yee, Jean Chai; Carey, Danielle (2019), "Anthropogenic marine debris found in peri-urban and urban mangroves on Penang Island, Malaysia", Mendeley Data, v1 http://dx.doi.org/10.17632/7tc9j8nynb.1

\section{References}

AbAbu-Hilal, A. H., \& Al-Najjar, T. (2004). Litter pollution on the Jordanian shores of the Gulf of Aqaba (Red Sea). Marine environmental research, 58(1), 39-63.

Aguilera, M. A., Broitman, B. R., \& Thiel, M. (2016). Artificial breakwaters as garbage bins: Structural complexity enhances anthropogenic litter accumulation in marine intertidal habitats. Environmental pollution, 214, 737-747. DOI: https://doi. org/10.1016/j.envpol.2016.04.058.

Almahasheer, H., Serrano, O., Duarte, C. M., Arias-Ortiz, A., Masque, P., \& Irigoien, X. (2017). Low carbon sink capacity of Red Sea mangroves. Scientific reports, 7(1), 9700. DOI: https://doi.org/10.1038/s41598017-10424-9.

Alongi, D. M. (2008). Mangrove forests: Resilience, protection from tsunamis, and responses to global climate change. Estuarine, Coastal and Shelf Science, 76(1), 1-13. DOI: https://doi.org/10.1016/j. ecss.2007.08.024.

Barnes, D. K., Galgani, F., Thompson, R. C., \& Barlaz, M. (2009). Accumulation and fragmentation of plastic debris in global environments. Philosophical Transactions of the Royal Society B: Biological Sciences, 364(1526), 1985-1998. DOI: https://doi. org/10.1098/rstb.2008.0205.
Browne, M. A., Crump, P., Niven, S. J., Teuten, E., Tonkin, A., Galloway, T., \& Thompson, R. (2011). Accumulation of microplastic on shorelines woldwide: Sources and sinks. Environmental science \& technology, 45(21), 9175-9179. DOI: https://doi. org/10.1021/es201811s.

Browne, M. A., Chapman, M. G., Thompson, R. C., Amaral Zettler, L. A., Jambeck, J., \& Mallos, N. J. (2015). Spatial and temporal patterns of stranded intertidal marine debris: Is there a picture of global change? Environmental Science \& Technology, 49(12), 7082-7094. DOI: https://doi. org/10.1021/es5060572.

Carslaw, D. C., \& Ropkins, K. (2012). Openairan $\mathrm{R}$ package for air quality data analysis. Environmental Modelling \& Software, 27, 52-61. DOI: https://doi.org/10.1016/j. envsoft.2011.09.008.

Cheal, A. J., MacNeil, M. A., Emslie, M. J., \& Sweatman, H. (2017). The threat to coral reefs from more intense cyclones under climate change. Global change biology, 23(4), 1511-1524. DOI: https://doi. org/10.1111/gcb.13593.

Chee, S. Y., Othman, A. G., Sim, Y. K., Adam, A. N. M., \& Firth, L. B. (2017). Land reclamation and artificial islands: Walking the tightrope between development and conservation. Global ecology and conservation, 12, 80-95. DOI: https://doi. org/10.1016/j.gecco.2017.08.005.

Cheshire, A., \& Adler, E. (2009). UNEP/IOC guidelines on survey and monitoring of marine litter.

Cordeiro, C. A. M. M., \& Costa, T. M. (2010). Evaluation of solid residues removed from a mangrove swamp in the São Vicente Estuary, SP, Brazil. Marine pollution bulletin, 60(10), 1762-1767. DOI: https:// doi.org/10.1016/j.marpolbul.2010.06.010.

Costanza, R., de Groot, R., Sutton, P., Van der Ploeg, S., Anderson, S. J., Kubiszewski, I., ... \& Turner, R. K. (2014). Changes in 
the global value of ecosystem services. Global environmental change, 26, 152158. DOI: https://doi.org/10.1016/j. gloenvcha.2014.04.002.

Cunningham, D. J., \& Wilson, S. P. (2003). Marine debris on beaches of the Greater Sydney Region. Journal of Coastal Research, 421-430.

Araújo, M. C. B., \& da Costa, M. F. (2007). Visual diagnosis of solid waste contamination of a tourist beach: Pernambuco, Brazil. Waste Management, 27(6), 833-839. DOI: https:// doi.org/10.1016/j.wasman.2006.04.018.

Debrot, A. O., Tiel, A. B., \& Bradshaw, J. E. (1999). Beach debris in Curacao. Marine Pollution Bulletin, 38(9), 795801. DOI: https://doi.org/10.1016/S0025326X(99)00043-0.

Debrot, A. O., Bron, P. S., Leon, R., \& Meesters, H. W. G. (2013). Marine debris in mangroves and on the seabed: Largelyneglected litter problems. Marine Pollution Bulletin, 72(1), 1-1. DOI: https://doi. org/10.1016/j.marpolbul.2013.03.023.

Derraik, J. G. (2002). The pollution of the marine environment by plastic debris: A review. Marine Pollution Bulletin, 44(9), 842-852. DOI: https://doi.org/10.1016/ S0025-326X(02)00220-5.

Duarte, C. M., Losada, I. J., Hendriks, I. E., Mazarrasa, I., \& Marbà, N. (2013). The role of coastal plant communities for climate change mitigation and adaptation. Nature Climate Change, 3(11), 961-968. DOI: https://doi.org/10.1038/nclimate1970.

Erikson, C., \& Burton, H. (2003). Origins and biological accumulation of plastic particles in fur seals from Macquarie Island. Ambio (ISSN: 0044-7447), 32: 380-384.

Eriksson, C., Burton, H., Fitch, S., Schulz, M., \& van den Hoff, J. (2013). Daily accumulation rates of marine debris on subAntarctic island beaches. Marine pollution bulletin, 66(1-2), 199-208. DOI: https://doi. org/10.1016/j.marpolbul.2012.08.026.
Galgani, F., Hanke, G., \& Maes, T. (2015). Global distribution, composition and abundance of marine litter. In Marine anthropogenic litter (pp. 29-56). Springer, Cham. DOI: 10.1007/978-3-319-16510-3.

Ganesapandian, S., Manikandan, S., \& Kumaraguru, A. K. (2011). Marine litter in the northern part of Gulf of Mannar, southeast coast of India. Research Journal of Environmental Sciences, 5(5), 471-478. DOI: https://doi.org/10.3923/ rjes.2011.471.478.

Giesen, W., Wulffraat, S., Zieren, M., \& Scholten, L. (2006). Mangrove guidebook for Southeast Asia, (part II). The Netherlands: FAO and Wetlands International, 7.

Goto, T., \& Shibata, H. (2015). Changes in abundance and composition of anthropogenic marine debris on the continental slope off the Pacific coast of northern Japan, after the March 2011 Tohoku earthquake. Marine Pollution Bulletin, 95(1), 234-241. DOI: https://doi. org/10.1016/j.marpolbul.2015.04.011.

Hamdan, O., Aziz, H. K., Shamsudin, I., \& Barizan, R. R. (2012). Status of mangroves in Peninsular Malaysia, Forest Research Institute Malaysia.

Hamilton, S. E., \& Casey, D. (2016). Creation of a high spatio-temporal resolution global database of continuous mangrove forest cover for the 21st century (CGMFC-21). Global Ecology and Biogeography, 25(6), 729-738. DOI: https://doi.org/10.1111/ geb.12449.

Hezri, A. A. (2019). Socio-demographic aspects of environmental change in Malaysia. Kuala Lumpur, Malaysia. 2019, p.218.

Hinojosa, I. A., \& Thiel, M. (2009). Floating marine debris in fjords, gulfs and channels of southern Chile. Marine Pollution Bulletin, 58(3), 341-350. DOI: https://doi. org/10.1016/j.marpolbul.2008.10.020.

Hong, S., Lee, J., Kang, D., Choi, H. W., \& Ko, S. H. (2014). Quantities, composition, 
and sources of beach debris in Korea from the results of nationwide monitoring. Marine Pollution Bulletin, 84(1-2), 27-34. DOI: https://doi.org/10.1016/j. marpolbul.2014.05.051.

ICCS. (2009). 18th International Coastal Cleanup Singapore - Reported results. Retrieved from http://coastalcleanup.nus. edu.sg/.

do Sul, J. A. I., \& Costa, M. F. (2013). Plastic pollution risks in an estuarine conservation unit. Journal of Coastal Research, 65(sp1), 48-54. DOI: https://doi.org/10.2112/SI65009.1 .

do Sul, J. A. I., Costa, M. F., \& Fillmann, G. (2014). Microplastics in the pelagic environment around oceanic islands of the Western Tropical Atlantic Ocean. Water, Air, \& Soil Pollution, 225(7), 2004. DOI: https:// doi.org/10.1007/s11270-014-2004-z.

Katsanevakis, S., \& Katsarou, A. (2004). Influences on the distribution of marine debris on the seafloor of shallow coastal areas in Greece (Eastern Mediterranean). Water, Air, and Soil Pollution, 159(1), 325-337. DOI: https://doi.org/10.1023/ B:WATE.0000049183.17150.df.

Kitamura, S., C. Anwar, A. Chaniago, \& S. Baba. (1997). Handbook of Mangroves in Indonesia; Bal \& Lombok. Denpasar: The Development of Sustainable Mangrove Management Project, Ministry of Forest Indonesia and Japan International Cooperation Agency.

Leite, A. S., Santos, L. L., Costa, Y., \& Hatje, V. (2014). Influence of proximity to an urban center in the pattern of contamination by marine debris. Marine Pollution Bulletin, 81(1), 242-247. DOI: https://doi. org/10.1016/j.marpolbul.2014.01.032.

Lourenço, P. M., Serra-Gonçalves, C., Ferreira, J. L., Catry, T., \& Granadeiro, J. P. (2017). Plastic and other microfibers in sediments, macroinvertebrates and shorebirds from three intertidal wetlands of southern
Europe and west Africa. Environmental Pollution, 231, 123-133. DOI: https://doi. org/10.1016/j.envpol.2017.07.103.

Martin, C., Almahasheer, H., \& Duarte, C. M. (2019). Mangrove forests as traps for marine litter. Environmental Pollution, 247, 499-508. DOI: https://doi.org/10.1016/j. envpol.2019.01.067.

McGranahan, G., Balk, D., \& Anderson, B. (2007). The rising tide: Assessing the risks of climate change and human settlements in low elevation coastal zones. Environment and urbanization, 19(1), 17-37. DOI: https:// doi.org/10.1177/0956247807076960.

Mcleod, E., Chmura, G. L., Bouillon, S., Salm, R., Björk, M., Duarte, C. M., ... \& Silliman, B. R. (2011). A blueprint for blue carbon: Toward an improved understanding of the role of vegetated coastal habitats in sequestering CO2. Frontiers in Ecology and the Environment, 9(10), 552-560. DOI: https://doi.org/10.1890/110004.

MetMalaysia. (2017). Jadual Pasang Surut Malaysia 2017: Tide Tables. Pusat Hidrografi Nasional, Malaysia.

Mok, O. (2019). Curtains for Jelutong landfill, says Penang island mayor. The Malay Mail. Retrieved on 22 June 2019. Available at: https://www.malaymail. com/news/malaysia/2019/02/22/curtainsfor-jelutong-landfill-says-penang-islandmayor/1725502

Moore, C. J. (2008). Synthetic polymers in the marine environment: A rapidly increasing, long-term threat. Environmental Research, 108(2), 131-139. DOI: https://doi. org/10.1016/j.envres.2008.07.025.

Mordecai, G., Tyler, P. A., Masson, D. G., \& Huvenne, V. A. (2011). Litter in submarine canyons off the west coast of Portugal. Deep Sea Research Part II: Topical Studies in Oceanography, 58(23-24), 2489-2496. DOI: https://doi.org/10.1016/j. dsr2.2011.08.009. 
Nagelkerken, I., Kleijnen, S., Klop, T., Van Den Brand, R. A. C. J., de La Moriniere, E. C., \& Van der Velde, G. (2001). Dependence of Caribbean reef fishes on mangroves and seagrass beds as nursery habitats: A comparison of fish faunas between bays with and without mangroves/seagrass beds. Marine Ecology Progress Series, 214, 225-235. DOI: https://doi.org/10.3354/ meps214225.

Naji, A., Esmaili, Z., \& Khan, F. R. (2017). Plastic debris and microplastics along the beaches of the Strait of Hormuz, Persian Gulf. Marine Pollution Bulletin, 114(2), 1057-1062. DOI: https://doi.org/10.1016/j. marpolbul.2016.11.032.

Newman, S., Watkins, E., Farmer, A., Ten Brink, P., \& Schweitzer, J. P. (2015). The economics of marine litter. In Marine anthropogenic litter (pp. 367-394). Cham: Springer. DOI: 10.1007/978-3-319- 165103.

Nor, N. H. M., \& Obbard, J. P. (2014). Microplastics in Singapore's coastal mangrove ecosystems. Marine Pollution Bulletin, 79(1-2), 278-283. DOI: https:// doi.org/10.1016/j.marpolbul.2013.11.025.

NOAA National Oceanic and Atmospheric Administration. (2018). Marine Debris Program Accomplishment Report. Available at: https://marinedebris.noaa.gov/ sites/default/files/publications-files/2018 NOAA_MDP_Accomplishments Report 508 0.pdf.

Nordhaus, I., Siriwardane, R., Gillis, L. G., Chee, S. Y., Chong, L., Firth, L., ... \& Suppiah, R. A. P. (2019). The future of mangroves in Penang, Malaysia: Bridging science, policy \& perspectives. DOI: 10.21244/ zmt.2019.001.

Possatto, F. E., Spach, H. L., Cattani, A. P., Lamour, M. R., Santos, L. O., Cordeiro, N. M., \& Broadhurst, M. K. (2015). Marine debris in a world heritage listed Brazilian estuary. Marine Pollution Bulletin, 91(2),
548-553. DOI: https://doi.org/10.1016/j. marpolbul.2014.09.032.

Primavera, J. H., Sadaba, R. B., Lebata, M. J. H. L., \& Altamirano, J. P. (2004). Handbook of mangroves in the Philippines: Panay. SEAFDEC.

Rech, S., Macaya-Caquilpán, V., Pantoja, J. F., Rivadeneira, M. M., Madariaga, D. J., \& Thiel, M. (2014). Rivers as a source of marine litter-a study from the SE Pacific. Marine Pollution Bulletin, 82(12), 66-75. DOI: https://doi.org/10.1016/j. marpolbul.2014.03.019.

Rochman, C. M., Hoh, E., Kurobe, T., \& Teh, S. J. (2013). Ingested plastic transfers hazardous chemicals to fish and induces hepatic stress. Scientific Reports, 3, 3263. DOI: https://doi.org/10.1038/494169a.

Ryan, P. G., Moore, C. J., van Franeker, J. A., \& Moloney, C. L. (2009). Monitoring the abundance of plastic debris in the marine environment. Philosophical Transactions of the Royal Society B: Biological Sciences, 364(1526), 1999-2012. DOI: https://doi. org/10.1098/rstb.2008.0207.

Sadri, S. S., \& Thompson, R. C. (2014). On the quantity and composition of floating plastic debris entering and leaving the Tamar Estuary, Southwest England. Marine Pollution Bulletin, 81(1), 5560. DOI: https://doi.org/10.1016/j. marpolbul.2014.02.020.

Sánchez, P., Masó, M., Sáez, R., De Juan, S., Muntadas, A., \& Demestre, M. (2013). Baseline study of the distribution of marine debris on soft-bottom habitats associated with trawling grounds in the northern Mediterranean. Scientia Marina, 77(2), 247-255. DOI: https://doi.org/10.3989/ scimar03702.10A.

Santos, I. R., Friedrich, A. C., \& Barretto, F. P. (2005). Overseas garbage pollution on beaches ofnortheastBrazil.MarinePollution Bulletin, 50(7), 783-786. DOI: https://doi. org/10.1016/j.marpolbul.2005.04.044. 
Schlining, K., Von Thun, S., Kuhnz, L., Schlining, B., Lundsten, L., Stout, N. J., ... \& Connor, J. (2013). Debris in the deep: Using a 22-year video annotation database to survey marine litter in Monterey Canyon, central California, USA. Deep Sea Research Part I: Oceanographic Research Papers, 79, 96-105. DOI: https://doi.org/10.1016/j. dsr.2013.05.006.

Seto, K. C., Fragkias, M., Güneralp, B., \& Reilly, M. K. (2011). A meta-analysis of global urban land expansion. PloS one, 6(8), e23777. DOI: https://doi.org/10.1371/ journal.pone.0023777.

Silva-Iñiguez, L., \& Fischer, D. W. (2003). Quantification and classification of marine litter on the municipal beach of Ensenada, Baja California, Mexico. Marine Pollution Bulletin, 46(1), 132-138. DOI: $\quad$ https://dx.doi.org/10.1016/S0025326X(02)00216-3.

Singare, P. U. (2012). Quantification study of non-biodegradable solid waste materials accumulated in the mangroves of Mahim Creek, Mumbai. Marine Science, 2(1), 1-5. DOI: $10.5923 /$ j.ms.20120201.01.

Sivasothi, N. (2002). Battling the Curse of Marine Litter. Nature Watch, 10(3).

Smith, S. D., \& Markic, A. (2013). Estimates of marine debris accumulation on beaches are strongly affected by the temporal scale of sampling. PLoS One, 8(12), e83694. DOI: https://doi.org/10.1371/journal.pone. 0083694.

Spalding, M., Wood, L., Fitzgerald, C., \& Gjerde, K. (2010). The 10\% target: Where do we stand. Global ocean protection: Present status and future possibilities, 96.

Thiel, M., Hinojosa, I. A., Miranda, L., Pantoja, J. F., Rivadeneira, M. M., \& Vásquez, N. (2013). Anthropogenic marine debris in the coastal environment: A multi-year comparison between coastal waters and local shores. Marine Pollution Bulletin,
71(1-2), 307-316. DOI: https://doi. org/10.1016/j.marpolbul.2013.01.005.

Topçu, E. N., Tonay, A. M., Dede, A., Öztürk, A. A., \& Öztürk, B. (2013). Origin and abundance of marine litter along sandy beaches of the Turkish Western Black Sea Coast. Marine Environmental Research, 85, 21-28. DOI: https://doi.org/10.1016/j. marenvres.2012.12.006.

Uhrin, A. V., \& Schellinger, J. (2011). Marine debris impacts to a tidal fringing-marsh in North Carolina. Marine Pollution Bulletin, 62(12), 2605-2610. DOI: https://doi. org/10.1016/j.marpolbul.2011.10.006.

United Nations Environment Programme (2017). Coastal crisis: Mangroves at risk. Available at: https://www.unenvironment. org/news-and-stories/story/coastal-crisismangroves-risk.

Vegter, A. C., Barletta, M., Beck, C., Borrero, J., Burton, H., Campbell, M. L., ... \& Gilardi, K. V. (2014). Global research priorities to mitigate plastic pollution impacts on marine wildlife. Endangered Species Research, 25(3), 225-247. DOI: https://doi. org/10.3354/esr00623.

Viehman, S., Vander Pluym, J. L., \& Schellinger, J. (2011). Characterization of marine debris in North Carolina salt marshes. Marine Pollution Bulletin, 62(12), 27712779. DOI: https://doi.org/10.1016/j. marpolbul.2011.09.010.

Watters, D. L., Yoklavich, M. M., Love, M. S., \& Schroeder, D. M. (2010). Assessing marine debris in deep seafloor habitats off California. Marine Pollution Bulletin, 60(1), 131-138. DOI: https://doi.org/10.1016/j. marpolbul.2009.08.019.

Williamson, P., Smythe-Wright, D., \& Burkill, P. (2016). Future of the Ocean and its Seas: A non-governmental scientific perspective on seven marine research issues of $\mathrm{G} 7$ interest. 2015-10. Available at: 
http://www. icsu. org/news-centre/news/pdf/ Report\% 20to\% 20G7\% 20SMins\% 20on\% 20FOSs. pdf.

Williams, A. T., \& Tudor., D. T. (2001). Temporal trends in litter dynamics at a pocket beach. Journal of Coastal Research, 17(1), 137145

World Bank. (2018). Global Waste to Grow by 70 Percent by 2050 Unless Urgent Action is Taken: World Bank Report. [online] World Bank. Available at: https://www.worldbank. org/en/news/press-release/2018/09/20/ global-waste-to-grow-by-70-percent-by2050-unless-urgent-action-is-taken-worldbank-report.

WWF (2019). Mangrove importance. [online] Wwf.panda.org. Available at: http:// wwf.panda.org/our_work/oceans/coasts/ mangroves/mangrove_importance/

Yeok, F. S., Aik, Y. C., \& Butt, C. (2016). A pilot rapid assessment of selected ecosystem services provided by the Teluk Air Tawar - Kuala Muda coast IBA in Pulau Pinang. DOI: https://doi.org/10.13140/ rg.2.2.24060.33927.

Yonkos, L. T., Friedel, E. A., Perez-Reyes, A. C., Ghosal, S., \& Arthur, C. D. (2014). Microplastics in four estuarine rivers in the Chesapeake Bay, USA. Environmental Science \& Technology, 48(24), 1419514202. DOI: https://doi.org/10.1021/ es5036317. 